\title{
Inter-Diffusion of Li-Isotopes in Liquid Lithium Metal
}

\author{
A. Otт and A. Lodding \\ Physics Department, Chalmers University of Technology, Gothenburg, Sweden \\ (Z. Naturforschg. 20 a, 1578-1582 [1965]; received 25 July 1965)
}

\begin{abstract}
The inter-diffusion coefficient of ${ }^{6} \mathrm{Li}$ and ${ }^{7} \mathrm{Li}$ in liquid $\mathrm{Li}$ metal has been measured by a capillaryreservoir vacuum lock technique and by mass spectrometric analysis. For the temperature interval $195-450{ }^{\circ} \mathrm{C}$ and near-normal isotopic composition, the results can be represented by

$$
D=(1.41 \pm 0.12) \cdot 10^{-3} \exp [-(2825 \pm 90) /(R T)] \text {. }
$$

Theoretical relations connecting diffusion and viscosity are well obeyed. Fair agreement is obtained with the Cohen-Turnbull free volume theory, if $\mathrm{Li}^{+}$is the diffusing species.
\end{abstract}

In a systematic investigation, in progress at this laboratory, of the atom mobilities in liquid metals, the diffusive behaviour of liquid lithium, the lightest of all metals, is of special interest. In the first place it has been the aim of this investigation to collect further systematic trends necessary for testing the validity of theoretical models. Another purpose was to shed more light on the disturbing fact that the diffusion values obtained by capillary methods may depend on the capillary diameter ${ }^{1,2}$.

\section{Experimental}

As in earlier investigations in this laboratory ${ }^{2,3}$ a capillary-reservoir method was adopted. Two special practical problems had to be tackled working with molten lithium, the first being the absence of a radioisotope, the second the exceptional reactivity of the metal.

The first problem was easily solved by the use of stable isotopes. Lithium metal with natural composition $\left({ }^{7} \mathrm{Li} /{ }^{6} \mathrm{Li} \cong 12.3\right.$, from $\mathrm{K}$ o c h $-\mathrm{Ligh} \mathrm{t}$ Co, $99.999 \%$ pure) was diffused out of the open end of a capillary into a reservoir with isotopically enriched metal $\left({ }^{7} \mathrm{Li} /{ }^{6} \mathrm{Li} \cong 31.0, \mathrm{Lith}\right.$ i u m C or p. of America, 99.9\% pure). The diffusion coefficient is given by

$$
\frac{c_{0}-c^{\prime}}{\bar{c}-c^{\prime}}=\frac{8}{\pi^{2}} \sum_{n=0}^{\infty} \frac{1}{(2 n+1)^{2}} \exp \left\{-\frac{(2 n+1)^{2} \pi^{2} D t}{4 l^{2}}\right\},
$$

where $c_{0}$ is the "normal" concentration of ${ }^{6} \mathrm{Li}$ in the capillary before the diffusion $\left(c_{0} \cong 0.075\right), c^{\prime}$ the

1 G. Careri, A. Paoletti, and M. Vicentini, Nuovo Cim. (10) 10,88 [1958]. reservoir concentration $\left(c^{\prime} \cong 0.031\right), \bar{c}$ the mean ${ }^{6} \mathrm{Li}$ concentration in the capillary after the diffusion, $l$ the capillary length and $t$ the duration of diffusion. If the ratio on the left is 0.7 or less, it is more than adequate to use only the first two terms.

The reactivity of lithium with air required the use of a vacuum lock. Also, as molten Li violently attacks vitreous material, all glass details had to be shielded from spatter. Metal containers and capillaries were made from $\mathrm{Va}$-Cr-steel, which was found to resist appreciable attack up to $500{ }^{\circ} \mathrm{C}$.

a) Apparatus and procedure. The principle of the experimental cell is shown in Fig. 1. The thin walled steel capillaries, $30-45 \mathrm{~mm}$ long, had in general 0.6 mm inner diameter, but about a third of the capillaries were wider, ranging from 0.8 to $1.1 \mathrm{~mm}$ inner diameter, in order to detect any systematic "skin-effect". Three capillaries (A) at a time were mounted in a steel holder at one end of a hollow steel tube (B), the other end of which could be attached to a stirrer. The tube passed through a teflon stopper (C) into the upper tube (D). This volume, some $35 \mathrm{~mm}$ inner diameter, could be closed off by a large glass valve (E), $30 \mathrm{~mm}$ opening, and evacuated or filled with argon via another valve $(\mathrm{F})$. Via a tapered joint (J) it could be connected to either the "diffusion tube" (G) or the "filling tube" $(\mathrm{H})$, each of which could be separately closed (valves I and $\mathrm{K}$ ) and evacuated or flushed (L and $\mathrm{M}$ ). The steel containers $(\mathrm{N}, \mathrm{O})$ containing about $20 \mathrm{~cm}^{3}$ lithium each, were temperature monitored by thermocouples (not shown in fig.) fused through the walls of $\mathrm{G}$ and $\mathrm{H}$. The diffusion tube contained the enriched metal reservoir, the filling tube the "normal" metal from which the capillaries were filled. The stabilized heaters $(\mathrm{P}, \mathrm{Q})$ for tubes $\mathrm{N}$ and $\mathrm{O}$ were Kanthal-wound, with the windings so arranged as to maintain a slight temperature gradient along the capillaries; the reservoir was some $1-2$ degrees warmer at the upper end than

\footnotetext{
2 J.Rohlin and A.Lodding, Z. Naturforschg. 17 a, 1081 [1962].

3 A. Lodding, Z. Naturforschg. 11 a, 200 [1956].
} 

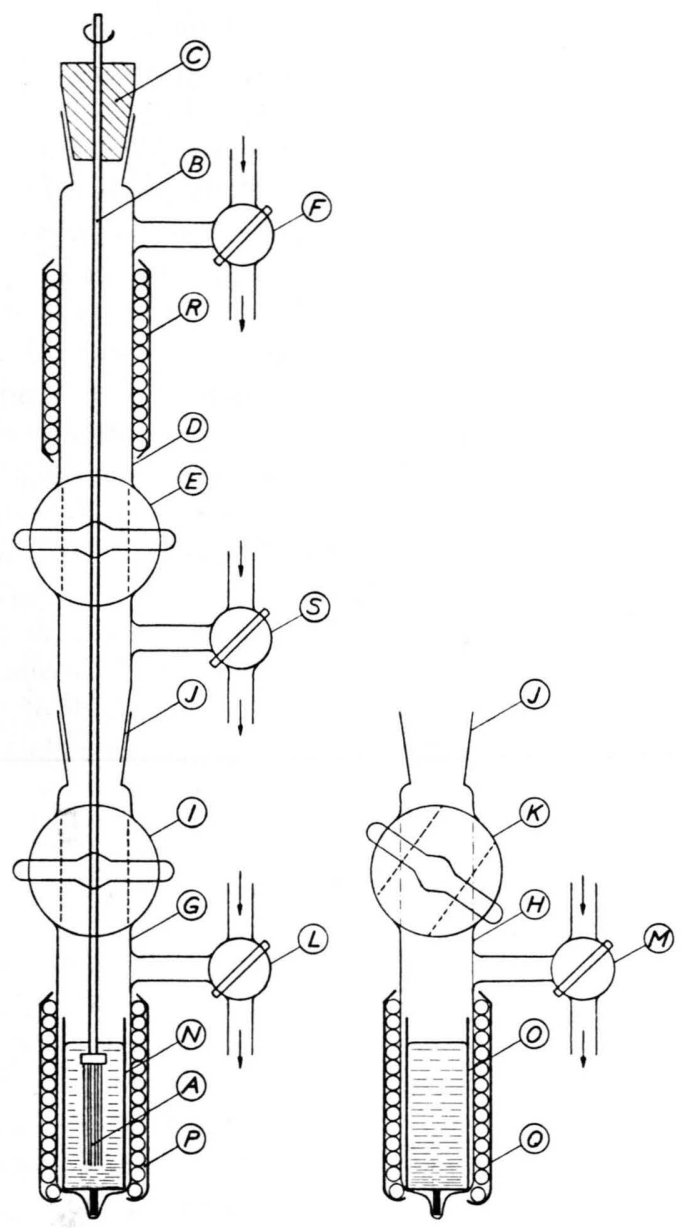

Fig. 1. Experimental cell for diffusion measurements in liquid lithium. For explanation of symbols, see section 1 a in text.

at the bottom, with the aim of avoiding convection. The Kanthal-wound oven (R) kept the "upper tube" at about $200{ }^{\circ} \mathrm{C}$, to prevent metal in newly filled capillaries from solidifying. A T-valve (S) was used to evacuate or flush the tapered joint (J). By a straightforward vacuum-lock procedure, permitting only argon or vacuum (ca. $10^{-3} \mathrm{~mm} \mathrm{Hg}$ ) next to the molten metal, the holder with empty capillaries was introduced into the filling tube $(\mathrm{H})$ above the "filling" metal, which, as well as that in the then closed diffusion reservoir, was kept at the intended diffusion temperature. The filling tube was evacuated, the capillary orifices were submerged and argon pressure was reinstated, pushing the metal into the evacuated capillaries. By another vacuum lock procedure the capillaries were pulled up into upper tube (D) and then in a similar way introduced into the diffusion tube $(\mathrm{G})$, above the reservoir. After temperature stabilizing, the capillaries were submerged about $4 \mathrm{~cm}$ below the surface. The stirrer was connect-

4 A. Lundén, S. Christofferson, and A. Lodding, Trans. Chalmers Univ. Techn. no. 221, 1959. ed to the holder tube (B) and rotated at about $15 \mathrm{r} / \mathrm{min}$. After 2-10 hours' diffusing time, the capillaries were pulled out into the upper tube and allowed to cool, then taken out into the open and detached from the holder. The metal on the outside of each capillary was removed, first mechanically, then with acid. The metal inside was then leached out with dilute $\mathrm{HNO}_{3}$ and converted to $\mathrm{LiNO}_{3}$ for mass analysis. A sample was also made after each run of the small amounts of lithium stuck to the holder, to keep check on any changes in the isotopic composition of the diffusing reservoir (after 20 runs the ${ }^{7} \mathrm{Li} /{ }^{6} \mathrm{Li}$ ratio had gone down from 31.3 to 30.2 ).

b) Isotopic analysis. The isotope ratio of each sample was measured using a $60^{\circ}$ deflection, $8^{\prime \prime}$ radius magnet NIER-type mass spectrometer, described earlier ${ }^{4}$, but considerably improved since. A vacuum lock has been constructed, so that the sample holding filament of the thermal emission ion source could be introduced and removed without loss of pumping time, enabling two samples an hour to be analysed, including "baking out" time after each sample. During "baking out" the ionizing filament was heated to some $2500{ }^{\circ} \mathrm{C}$ and the ionization chamber to some $600{ }^{\circ} \mathrm{C}$. During operation, the corresponding temperatures were $500^{\circ}$ and $200^{\circ} \mathrm{C}$. Although whole $\mathrm{LiNO}_{3}$ molecules were thought to be evaporated from the sample holder, and the fractionation correction thus would be $\sqrt{69 / 68}$, care was taken, in case fragments also were present, to maintain the same temperatures, vacuum, and geometry for all samples, thus avoiding error in relative values. The ion currents were plotted, via a $10^{11} \Omega$ resistance and a vibrating reed electrometer, on a recorder chart and compared using an automatic magnet current selector with an attenuator switching device. A detailed description of the ion source assembly and vacuum lock is under preparation.

The reproducibility of the measured ${ }^{7} \mathrm{Li} /{ }^{6} \mathrm{Li}$ ratios was better than $0.3 \%$.

\section{Results and Accuracy}

The determined values of the diffusion coefficient are given in Table 1 and plotted in Fig. 2. The best straight Arrhenius line has been calculated to be

$$
\begin{aligned}
D=(1.41 \pm 0.12) & \cdot 10^{-3} \\
& \cdot \exp [-(2825 \pm 90) / R T] \mathrm{cm}^{2} / \mathrm{sec} .
\end{aligned}
$$

The plus-sign in the pre-exponential term (where the larger value of two computed standard errors has been accepted) corresponds to the plus-sign in the exponent. The calculable error arises from an uncertainty in capillary length and from mass analysis error. The effective capillary length can be influenced by the amount of stirring ${ }^{5}$, but experiments with different values of $l$ gave no indication

5 L. Nanis, S. R. Richards, and J. O'M. Bockris, Rev. Sci. Instr. 36, 673 [1965]. 


$\left.\begin{array}{|c|c|c|}\hline \begin{array}{c}\text { Temp. } \\ { }^{\circ} \mathrm{C}\end{array} & \begin{array}{c}D \cdot 10^{5} \\ \mathrm{~cm}^{2} / \mathrm{s}\end{array} & \begin{array}{c}\text { Capill. diam. } \\ \mathrm{mm}\end{array} \\ \hline 196 \pm 2 & 6.55 \pm 0.30 & 0.6 \\ 196 \pm 2 & 6.67 \pm 0.25 & 0.6\end{array}\right\}$

Table 1. Diffusion coefficient of ${ }^{6} \mathrm{Li}$ in liquid lithium, experimental results.

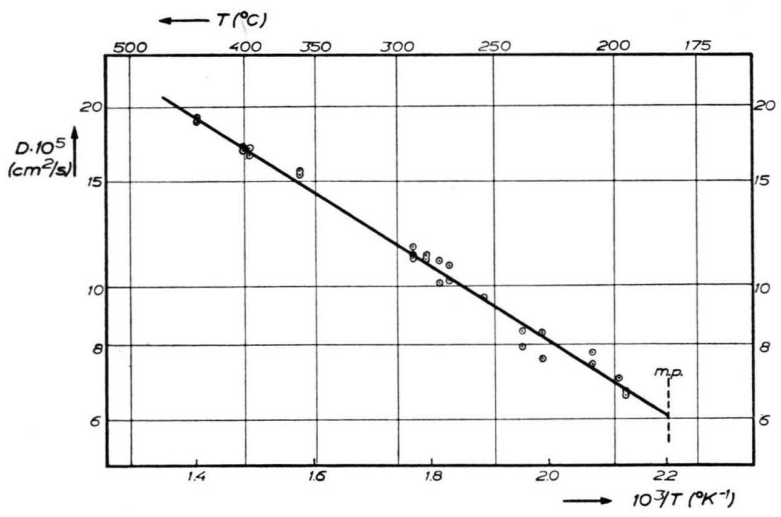

Fig. 2. Arrhenius plot of the isotope interdiffusion coefficient in liquid lithium.

of a contribution greater than $0.1 \mathrm{~mm}$. The possible error in 1 was assessed to be $0.4 \mathrm{~mm}$, corresponding to an error in $D$ of some $2 \%$. The inaccuracy in $D$ arising from mass spectrometry was calculated to be $1.0-2.0 \%$. Each $D$-value in Table 1 was ac-

6 The possibility of convection, suggested by Cordes and DöGE ${ }^{7}$, can probably be ruled out in the cases of $\mathrm{K}^{2}$, as the metal reservoir was kept under a temperature gradient of the same direction and magnitude as in the present investi- cordingly assigned an error of max. $4 \%$ from these sources. The error in temperature varied from $\pm 2{ }^{\circ} \mathrm{C}$ at $200{ }^{\circ} \mathrm{C}$ to $\pm 8{ }^{\circ} \mathrm{C}$ at $400{ }^{\circ} \mathrm{C}$.

More serious sources of error were occlusions or bubbles in the capillaries. In earlier self-diffusion measurements ${ }^{2,3}$ at this laboratory such errors could be avoided by visual inspection of the glass capillaries before and after anneal. Thus in the case of $\mathrm{K}$ roughly $25 \%$ of all capillaries were discarded because of breaks in the metal column. The opaque capillary walls in the present investigation made such sorting out impossible. The criterium adopted was, that in each run with 3 capillaries the $D$-values which departed by more than $20 \%$ from the highest value were discarded. About $28 \%$ of all capillaries were thus sorted out, in good agreement with the potassium percentage. Of the discarded $D$-values, the greatest share by far were below one-fifth of the accepted values, indicating obstruction near the capillary opening.

\section{Discussion}

a) Dependence of results on capillary diameter. It can be seen from Table 1 that the $D$-values obtained in capillaries wider than $0.6 \mathrm{~mm}$ inner diameter show no definite tendency to deviate from the $0.6 \mathrm{~mm}$ series. Where different diameters were used in one run, the wider diameter gave lower $D$-values in 4 cases and higher values in 3 cases; the deviation in either direction is $5 \%$ on the average. Thus no "skin-effect" could be detected for lithium in steel capillaries, and the reason for the diameter effect found in In and $\mathrm{K}$ is still rather obscure and should be further investigated. The most plausible explanation at present seems to be chemical trapping of tracer indium in steel capillary walls and of tracer potassium in glass walls ${ }^{6}$.

b) Inter-diffusion and self-diffusion. It must be anticipated that the inter-diffusion coefficient may depend on the abundance ratio of the isotopes. Experiments with lithium of high ${ }^{6} \mathrm{Li}$ concentration are therefore under preparation at this laboratory. The self-diffusion coefficients of ${ }^{6} \mathrm{Li}$ and ${ }^{7} \mathrm{Li}$ in their dependence on the isotopic composition of the melt are also of interest and can perhaps be measured by the

gation. CARERI et al. ${ }^{1}$ took similar precautions to limit convection in In.

7 H. Cordes and G. Döge, Z. Naturforschg. 18 a, 264 [1963]. 
NMR method. On the basis of viscosity measurements by Ban, Randall, and Montgomery ${ }^{8}$, who have found up to about $40 \%$ difference between the viscosities of pure ${ }^{6} \mathrm{Li}$ and ${ }^{7} \mathrm{Li}$, a large difference of corresponding self-diffusion coefficients should be expected.

To compare experimental results with some of the established models, diffusion coefficients describing the transport w.r.t. a quasi-lattice are needed. Let these microscopic coefficients be denoted by $D^{\prime}{ }_{6}$ and $D^{\prime}{ }_{7}$. The relation between them and the inter-diffusion coefficient $D$ is seen from the following reasoning:

The fluxes w.r.t. the quasi-lattice are

$$
J^{\prime}{ }_{6}=-n D_{6}^{\prime} \frac{\mathrm{d} c_{6}}{\mathrm{~d} x}, \quad J^{\prime}{ }_{7}=-n D_{7}^{\prime} \frac{\mathrm{d} c_{7}}{\mathrm{~d} x},
$$

and the fluxes w.r.t. the (closed) vessel are

$$
J_{6}=-n D \frac{\mathrm{d} c_{6}}{\mathrm{~d} x}, \quad J_{7}=-J_{6},
$$

$n$ being the molar concentration, $c_{6,7}$ the molar fractions $\left(c_{6}+c_{7}=1\right)$. Also

$$
J_{6}=J^{\prime}{ }_{6}+n c_{6} v_{\mathrm{L}}, \quad J_{7}=J^{\prime}{ }_{7}+n c_{7} v_{\mathrm{L}},
$$

where $v_{\mathrm{L}}$ is the velocity of the quasi-latice w.r.t. the vessel. Combining these equations,

$$
v_{\mathrm{L}}=\left(D^{\prime}{ }_{6}-D^{\prime}{ }_{7}\right) \mathrm{d} c_{6} / \mathrm{d} x \text {, }
$$

and

$$
D=\left(1-c_{6}\right) D_{6}^{\prime}+c_{6} D^{\prime}{ }_{7} \text {. }
$$

Since at present no reliable experimental information concerning these refinements is available, in the following section our experimental inter-diffusion coefficient will suffice to furnish comparison with existing theories of liquid self-diffusion.

c) Comparison with theories. The liquid self-diffusion theories of Eyring et al. ${ }^{9}$ and of Walls and
UPTHEGROVE ${ }^{10}$ both assume the reality of a classical activated jump mechanism for the viscosity process and deduce the self-diffusion coefficient from viscosity by a modified Stokes-Einstein relation. While the assumptions about the physical mechanism are open to objection on several grounds ${ }^{11}$, the connection betwen viscosity and diffusion has been established rather conclusively by the good agreement of the modified STokes-Einstein formula with recent accurate self-diffusion measurements. The relation has the form

$$
D=\frac{k T}{\left(V_{\mathrm{m}}\right)^{1 / 3} \xi \eta}
$$

where $k$ is Boltzmann's constant, $T$ abs. temperature, $\eta$ viscosity, $V_{\mathrm{m}}$ molecular volume and $\xi$ a constant which is about 5.6 in EYRING's theory and about 5.3 in that of WALLS and UPTHEGROVE.

It is evident from Table 2, that the agreement of the present data with formula (8) is very good. The tendency is present, especially at lower temperatures, for the experimental values to fall along a slightly steeper line in the $\ln D$ vs. $T^{-1}$ diagram. This seems to be the case for all diffusion data of some $10 \mathrm{me}-$ tals, presented by Walls and Upthegrove, and also for self-diffusion in $\mathrm{K}^{2}$ (not quoted in ref. ${ }^{10}$ ), where otherwise the agreement with formula (8) is good. This effect is somewhat reduced, if the temperature dependence of $\xi$ is taken into account. In Eyring's treatment it is specified, that $\xi$ should equal 6 for an ideal close-packed lattice, and the

\begin{tabular}{|c|c|c|c|c|}
\hline & $\begin{array}{c}D\left(T_{\mathrm{m}}\right) \cdot 10^{5} \\
\mathrm{~cm}^{2} / \mathrm{s}\end{array}$ & $D\left(1.5 T_{\mathrm{m}}\right) / D\left(T_{\mathrm{m}}\right)$ & Formula & Remark \\
\hline $\begin{array}{l}\text { Experimental } \\
\text { EYRING et al. } 9 \\
\text { EYRING et al., modif. } \\
\text { WALLS and UPTHEGROVE } 10 \\
\text { SWALIN } 17 \\
\text { CoHEN and TURNBULL } \\
\text {-" } 13 \text {, modif. }\end{array}$ & $\begin{array}{c}6.2 \\
6.65 \\
6.60 \\
6.85 \\
12.4 \\
6.50 \\
6.65\end{array}$ & $\begin{array}{l}2.80 \\
2.40 \\
2.50 \\
2.40 \\
2.25 \\
2.20 \\
2.45\end{array}$ & $\begin{array}{l}(8) \\
(8) \\
(8) \\
(11) \\
(12) \\
(12)\end{array}$ & $\begin{array}{l}\xi=5.6 \\
\xi \text { from }(10) \\
\xi=5.35 \\
K=5.94 \cdot 10^{3} \\
r=0.91 \AA ; V_{\mathrm{F}} / V_{\mathrm{m}}=3 \alpha T \\
r=0.81 \AA ; V_{\mathrm{F}} / V_{\mathrm{m}} \text { from }(9)\end{array}$ \\
\hline
\end{tabular}
correction to 5.6 is mainly due to the presence of free volume. If, in acordance with the treatment of $\mathrm{X}$-ray evidence by FuruKawa ${ }^{12}$, it is stipulated that the free volume fraction at the melting point is about equal for all metals, and if its value is taken as

Table 2. Comparison of experimental and theoretical self-diffusion coefficients at the melting point $T_{\mathrm{m}}$ of lithium and at $T=T_{\mathrm{m}} \cdot 1.5$. Values for molar volumes, viscosities and coefficients of thermal expansion are taken from ref. ${ }^{16}$.

8 N. T. Ban, C. M. Randall, and D. J. Montgomery, Phys. Rev. 128, 6 [1962].

9 H. Eyring and T. Ree, Proc. Nat. Acad. Sci. 47, 526 [1961].

$10 \mathrm{H}$. A. W $\mathrm{W}_{\text {alls }}$ and W. R. Upthegrove, Acta Met. 12, 461 [1964].
11 See, e.g., N.H. NACHTrieb, Liquid Metals and Solidification, Amer. Soc. Metals, 1958, p. 49.

12 K. Furukawa, Sci. Repts. Res. Inst. Tohoku Univ., Ser. A, 12, 368 [1960]. 
$\left(V_{\mathrm{F}} / V_{\mathrm{m}}\right) \cong 0.06$ (this choice is made partly to make $\xi_{\mathrm{m}} \cong 5.6$, partly because it appears to be a suitable parameter for other theories ${ }^{13-15}$ ) then one can write

and

$$
\begin{aligned}
V_{\mathrm{F}} / V_{\mathrm{m}} & =0.06+3 \alpha\left(T-T_{\mathrm{m}}\right) \\
\xi & =6\left[0.94-3 \alpha\left(T-T_{\mathrm{m}}\right)\right]
\end{aligned}
$$

where $3 \alpha$ is the volume expansion coefficient. This correction ( $\alpha$ taken from ref. ${ }^{16}$ ) improves the agreement of formula (8) with experiments, as can be seen in Table 2 .

The density fluctuation theory of Swalin ${ }^{17}$ marks a new approach, in allowing for the possibility of diffusion by position adjustments much smaller than interatomic distances, with the range of displacement lengths given by the probability of 5 nearest neighbors moving apart a corresponding distance. The mean displacement is calculable using the Monse function for the fluctuation energy. Swalin's model leads to the simple expression

$$
D=3.59 \cdot 10^{-6} T^{2} / K
$$

where $K$ is the "force constant" obtainable from compressibility measurements. Assuming $K$ to be the same for the liquid as for the solid, and using $K_{\mathrm{Li}}=5.94 \cdot 10^{3}$ from the data of $\mathrm{W}_{\mathrm{ASER}}$ and $\mathrm{P}_{\mathrm{AU}}$ LING ${ }^{18}$, the values in Table 2 are obtained. It is seen that the agreement of formula (11) with experiments on $\mathrm{Li}$ is poor. The $K$-value for the liquid should be if anything lower than for the solid ${ }^{18}$, which would aggravate the situation. A survey of availabe diffusion data of some 10 liquid metals ${ }^{15}$ indicates empirically that the diffusion coefficients should be approximately proportional to $K^{-1 / 2}$ rather than $K^{-1}$.

The free volume theory of CoHen and Turnbull ${ }^{13}$ avoids the concept of an activated state, but assumes, as in the "hole" theories, an elementary jump distance, given by the ionic radius. To make a step,

13 M. H. Cohen and D. Turnbull, J. Chem. Phys. 31, 1164 [1959].

14 N. H. Nachtrieb, E. Fraga, and Ch. Wahl, J. Phys. Chem. 67, 2353 [1963].

15 A. Lodning, to be published. the isoenergetic statistical redistribution of free volume must open up a void greater than approximately the ionic volume, and a second particle moves in to occupy the seat of the first. The treatment leads to

$$
D=\frac{1}{3} r \cdot u_{\mathrm{k}} \exp \left[-\left(\frac{4}{3} \pi \gamma r^{3}\right) / V_{\mathrm{F}}\right]
$$

where $u_{\mathrm{k}}$ is the gas kinetic particle velocity, $V_{\mathrm{F}}$ the free volume, $\gamma$ a constant between 0.5 and 1 , allowing for the overlap of free volume. The length $r$ is half the mean displacement, which should be equal to the radius of the critical volume sphere, and has been found in several instances (see, e. g., ref. ${ }^{14}$ ) to correspond to a little more than the ionic radius. Cohen and Turnbull use $V_{\mathrm{F}}=3 \alpha T V_{\mathrm{m}}$ for the free volume. This gives the values shown in Table 2 . The agreement with experiments in $\mathrm{Li}$ is acceptable if half the jumping distance is $0.91 \AA$, to be compared with the ionic radius for lithium $r_{\mathrm{i}}=0.6 \AA^{19}$. The temperature dependence expected is considerably smaller than observed. A much better fit is obtained, if the expression (9) for the free volume is used. As is shown in Table 2, the jumping distance is reduced to $0.81 \AA$ and the temperature dependence is increased. The size of the critical volume is, however, still large enough to house up to about three close-packed particles. The CoHen-Turnbull theory does not appear to exclude completely the possibility of diffusing "clusters", and the treatment could, with a slight modification, also be applied to such a case.

This research has been supported by the Swedish Technical Research Council and by Statens Naturvetenskapliga Forskningsråd. We are grateful to Prof. Dr. A. Klemm, Mainz, for valuable comments. Fil. kand. D. Andreasson and ing. H. Olsson have assisted us skilfully at various stages of the project. We are indebted to Mr. R. Eliasson for glass-blowing work and to ing. M. LövenBy for help with mass-spectrometry.

16 R. N. Lyon (ed.), Liquid Metals Handbook, 2nd edition, NAVEXOS P.733 (Rev.) [1954].

17 R. A. Swalin, Acta Met. 7, 736 [1959].

18 J. W ASER and L. PAuling, J. Chem. Phys. 18, 747 [1950].

19 L. Pauling, The Nature of the Chemical Bond, 2nd edition, Ithaca 1945. 